\title{
Effect of Dietary Ascorbyl-2-Phosphate on Immune Function after Transport to a Feeding Facility
}

\author{
P. J. Tyler and K. A. Cummins ${ }^{1}$ \\ Department of Animal Sciences, \\ Alabama Agricultural Experiment Station, \\ Auburn University, AL 36849
}

\section{ABSTRACT}

Effects of dietary ascorbyl-2-phosphate on immune function after a $210-\mathrm{km}$ trip were measured in $18 \mathrm{Hol}-$ stein heifers. After transport on d $0,10 \mathrm{~g}$ of ascorbyl2-phosphate each were added to the diets of 10 heifers, whereas eight heifers were fed a control diet. Plasma cortisol concentrations increased by an average of 25.6 $\mu \mathrm{g} / \mathrm{ml}$ on d 0 following transport, but by d 7 after transport had decreased to pretransport levels. Average daily gain was lower in heifers fed ascorbyl-2-phosphate from d 28 to $49 \mathrm{~d}$ after transport, but did not differ over the entire study. Feeding ascorbyl-2-phosphate maintained plasma ascorbate concentrations on d 7 post-transport, which decreased in control heifers. Plasma keyhole limpet hemocyanin antibody titers were significantly higher in control heifers from d 7 to 49. Mononuclear leukocyte proliferation responses were decreased on $\mathrm{d} 0$ in lymphocytes stimulated by mitogens, with pokeweed mitogen-stimulated cells showing less of a response than cells stimulated by the other mitogens. In the absence of mitogens, dietary ascorbyl-2-phosphate increased basal ${ }^{3} \mathrm{H}$-methyl thymidine incorporation by cultured lymphocytes. Across diets and mitogens, lymphocytes treated with cortisol showed decreased ${ }^{3} \mathrm{H}$ methyl thymidine incorporation. Transportation acted as a stressor, as evidenced by the increased plasma cortisol levels at d 0 immediately after transport, but immunological effects were not apparent by d 7. Feeding ascorbyl-2-phosphate maintained plasma ascorbate concentrations on $\mathrm{d} 7$, but had negative effects on immune responses posttransport.

(Key words: ascorbic acid, cattle, immune function)

Abbreviation key: A2P = Ascorbyl-2-phosphate magnesium, A2PP = ascorbyl-2-polyphosphate, $\operatorname{Con} \mathbf{A}=$ concanavalin A, cortisol = hydrocortisone-21-phosphate, HBSS = Hank's balanced salt solution, $\mathbf{K L H}=$

Received December 11, 2001.

Accepted April 30, 2002.

${ }^{1}$ Corresponding author: K. A. Cummins; e-mail: kcummins@ acesag.auburn.edu. keyhole limpet hemocyanin, MNL = mononuclear lymphocytes, PHA = phytohemagglutinin, $\mathbf{P W M}=$ pokeweed mitogen.

\section{INTRODUCTION}

Glucocorticoids, such as cortisol, which increase in plasma during stress, have well documented negative effects on the immune system (Parrillo and Fauci, 1979; Cupps and Fauci, 1982; Roth and Kaeberle, 1982; Sartin et al., 1988). Loading and transport used as stressors in cattle have been correlated with increases in plasma cortisol (Crookshank et al., 1979; Fell and Shutt, 1986; Mitchell et al., 1988; Ojo-Amaize et al., 1988; Agnes et al., 1990). Corticoids have been shown to decrease interleukin-2 production in vivo and in vitro (Blecha and Baker, 1986) and decrease in vitro proliferation of peripheral blood lymphocytes (Blecha and Baker, 1986; Gillis et al., 1979). Ascorbate has been shown to restore polymorphonuclear leukocyte function in scorbutic rhesus monkeys by restoring normal phenotype and improving phagocytosis and killing of bacteria (Goldshmidt, 1991). Ascorbic acid has also had a positive effect on cattle neutrophils following injection of dexamethasone by reversing decreases in neutrophil random migration, oxidative metabolism and antibody-dependent cell-mediated cytotoxicity (Roth and Kaeberle, 1985).

Plasma ascorbate concentrations decreased in calves stressed by housing conditions or disease (Cummins and Brunner, 1990; Salageanu et al., 1971). Dietary supplementation of calves with ascorbate has been shown to increase plasma ascorbate concentrations and concurrently improve antibody responses to an antigen (Cummins and Brunner, 1990). Ascorbate may also play a protective role in the immune system as a scavenger of free-radicals generated by phagocytic cells (Anderson and Lukey, 1987).

Feeding ascorbate to adult cattle results in rapid destruction of ascorbate in the rumen (Knight et al., 1941; Vavich et al., 1945). Ascorbyl-2-phosphate magnesium (A2P) has been used as a source of vitamin C in diets for several aquatic species (Sato et al., 1991; Shigueno 
Table 1. Composition of silage:concentrate mix.

\begin{tabular}{lc}
\hline & Percent DM \\
\hline Ingredient & \\
Corn grain, cracked & 41.1 \\
Soybean meal, 48\% CP & 33.1 \\
Corn silage & 21.4 \\
Mineral pellet 1 & 2.7 \\
Limestone & 1.1 \\
Dicalcium phosphate & 0.4 \\
Salt, trace mineral & 0.2 \\
Nutrient content & \\
DM, \% & 72.4 \\
NE, Mcal/kg ${ }^{2}$ & 1.18 \\
NE ${ }_{\mathrm{m}}$, Mcal/kg & \\
CP, $\%$ & 1.79 \\
ADF, \% & 21.1 \\
Ca, \% & 8.4 \\
P, \% & 1.1 \\
\hline
\end{tabular}

${ }^{1}$ Bovatec medicated feedlot pellet, Faithway Feed Co., Guntersville, AL.

${ }^{2}$ Calculated from NRC values (National Research Council, 1988).

and Itoh, 1988) and ascorbate in this form is more stable than is free ascorbic acid (Shigueno and Itoh, 1988). Nonspecific phosphatases convert A2P to free ascorbic acid in vivo (Shigueno and Itoh, 1988; Sato et al., 1991); however, the effect of dietary A2P on plasma ascorbate concentrations in cattle with functional rumens has not been investigated.

A study was conducted with its primary objective to evaluate the effects of dietary $\mathrm{A} 2 \mathrm{P}$ on plasma ascorbate concentrations, lymphocyte proliferation following stimulation with a mitogen, plasma antibody concentrations to a specific antigen, and growth in heifers with functional rumens following transport to a feeding facility. As a secondary objective, the effect of in vitro addition of cortisol on lymphocyte proliferation and possible interactions with different mitogens and dietary ascorbate were evaluated.

\section{MATERIALS AND METHODS}

Eighteen Holstein heifers, 9 to 13 mo of age, were blocked by weight and then within weight were assigned randomly to one of two treatments. Treatments started on $\mathrm{d} 0$ following transport to the feeding facility. Ten heifers received $10 \mathrm{~g} / \mathrm{d}$ of A2P (Showa Denko America, Inc., New York, NY) fed in $4.5 \mathrm{~kg}$ of a silage:concentrate mixture (Table 1), and eight control heifers received no A2P but were fed $4.5 \mathrm{~kg}$ of the silage:concentrate mixture. Ascorbyl-2-phosphate was fed as the magnesium salt, and contained 40 to $42 \%$ ascorbate on a DM basis. Diets for both groups consisted of the silage:concentrate mixture and free-choice coastal bermuda grass hay, and were offered from $2 \mathrm{wk}$ before the start of the study until its conclusion.
On d 0 , all heifers were transported in a cattle trailer for $210 \mathrm{~km}$ over a 2.3 -h period to the feeding facility. On $\mathrm{d}-2$ and 0 blood samples were taken from all heifers for use as covariants in subsequent statistical analyses and in order to confirm that plasma cortisol concentrations were increased on the day of transport. Day 0 samples were taken immediately after the heifers were unloaded from the trailer. The experimental period began after the $\mathrm{d} 0$ blood sample was taken and the heifers were given access to the experimental diets. Blood samples were also collected at 7, 14, 28, 35, 42 and $49 \mathrm{~d}$ after being transported. Plasma collected was held frozen at $-20^{\circ} \mathrm{C}$ until analyzed. Lymphocytes were isolated from fresh blood immediately after collection. The heifers were weighed on $\mathrm{d} 0$ after being unloaded from the trailer, and on d 28 and 49. Fifty milligrams of keyhole limpet hemocyanin (KLH) were injected subcutaneously at $d 0$ after transport and on $d 14$. Keyhole limpet hemocyanin was used as an innocuous antigen to which the heifers had not been previously exposed in order to evaluate antibody response to an antigenic challenge.

Plasma antibody titers to $\mathrm{KLH}$ were measured as previously described using an ELISA (Cummins and Brunner, 1989). Plasma levels of cortisol were measured using radioimmunoassay (Sartin et al., 1988), and ascorbic acid was measured using a colorimetric assay based on dipyridyl (Okamura, 1980). Plasma IgG concentrations were measured using a radial immunodiffusion kit (VMRD, Pullman, WA). All plasma samples were analyzed at the end of the study using a single assay and standard curve for each component measured.

\section{Leukocyte Isolation and Culture}

Blood was collected in preservative-free heparin, diluted with Hank's balanced salt solution (HBSS, Gibco, Gaithersburg, MD), layered over Histopaque-1077 (Sigma Chemical Co., St. Louis, MO) and centrifuged at $550 \times \mathrm{g}$ for $45 \mathrm{~min}$. The mononuclear lymphocyte (MNL) layer was removed and washed three times, and cells were diluted to $1.5 \times 10^{6}$ cells $/ \mathrm{ml}$ with $7.5 \times 10^{5}$ cells added to each well of a 96 -well microplate. Mononuclear lymphocytes from each heifer were cultured for each of four treatments in a $2 \times 2$ factorial arrangement. The treatments were dietary A2P at 0 or $10 \mathrm{~g} / \mathrm{d}$, and addition of hydrocortisone-21-phosphate (cortisol, Sigma Chemical Co.) added at a final concentration of $1 \times 10^{-}$ ${ }^{7} \mathrm{M}$ per well, or no cortisol. Within each treatment, MNL were cultured in triplicate with pokeweed mitogen (PWM, Gibco) diluted to 1/10th of recommended reconstitution in HBSS, phytohemagglutinin (PHA, Gibco) diluted to 1/10th of recommended reconstitution in HBSS, concanavalin A (ConA, Calbiochem, La Jolla, 
Table 2. Body weight and average daily gain in heifers following transport.

\begin{tabular}{lccc}
\hline & Control & $\begin{array}{l}\text { Ascorbyl- } \\
\text { 2-phosphate }\end{array}$ & $\begin{array}{l}\text { Pooled } \\
\text { SEM }\end{array}$ \\
\hline ADG, kg & & & \\
$0-27$ & 1.2 & 1.1 & 0.5 \\
$28-49^{\mathrm{a}}$ & 1.2 & 0.70 & 0.5 \\
$0-49$ & 1.1 & 1.0 & 0.3 \\
Initial BW, kg & 273 & 263 & 68 \\
\hline
\end{tabular}

${ }^{a}$ Effect of treatment, $P<0.001$.

CA) diluted to $0.1 \mathrm{mg} / \mathrm{ml}$ in HBSS, or no mitogen. Mitogens were added at one microliter per well. Cells were cultured for $48 \mathrm{~h}$ at $95 \% \mathrm{CO}_{2}: 5 \% \mathrm{O}_{2}$, labeled with ${ }^{3} \mathrm{H}$ methyl thymidine $(1 \mu \mathrm{Cu} /$ well, New England Nuclear, Boston, MA) and then frozen $18 \mathrm{~h}$ later at $-20^{\circ} \mathrm{C}$. Cells were harvested using a cell harvester and ${ }^{3} \mathrm{H}$-methyl thymidine incorporation was determined by liquid scintillation counting.

\section{Statistical Analysis}

Initial BW and average daily gains were analyzed by ANOVA using the SAS GLM procedure (SAS User's Guide, 1985). The data for KLH antibody titers, ascorbate, and cortisol concentrations were analyzed as a split-plot over time for a randomized complete block design, with diet, block, day, and diet $\times$ day as the main

\section{No Mitogen}
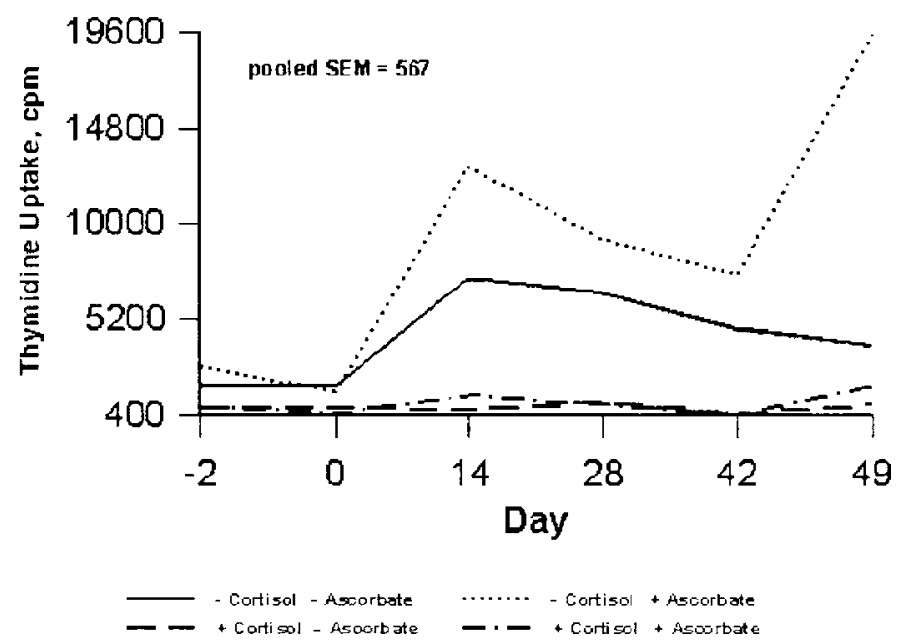

Figure 1. Proliferation of mononuclear lymphocytes with no mitogen. Proliferation was evaluated by ${ }^{3} \mathrm{H}$-methyl thymidine uptake. Day 0 was day of transport $210 \mathrm{~km}$ to feeding facility. Effect of cortisol $(P<0.001)$, dietary ascorbate $(P<0.01)$, and the interaction of cortisol and ascorbate $(P<0.05)$ were significant. effects in the model. Block had no effect on any variable. For the MNL proliferation, analysis was for a split-plot over time with diet, cortisol treatment, day, mitogen, animal within diet, and the two-way interactions of diet, day, cortisol, treatment, and mitogen included in the model. The SAS GLM procedure was used for all analyses (SAS User's Guide, 1985).

\section{RESULTS}

Growth and BW data for the experimental period are shown in Table 2. Body weight did not differ between groups $(P>0.1)$. Average daily gain was lower in heifers fed A2P from d 28 to d $49(P<0.001)$, but did not differ over the entire study $(P>0.1)$.

Plasma cortisol levels were not significantly affected during the experimental period (Table 3), but cortisol concentrations were elevated immediately after transporting heifers on $\mathrm{d} 0$ in both dietary groups relative to d $-2(P<0.05$, Table 4$)$. Diet had no effect on plasma cortisol concentrations $(P>0.1)$.

There were significant effects of day $(P<0.05)$, and diet $\times$ day $(P<0.1)$ on plasma ascorbate concentrations (Tables 3 and 4). Plasma ascorbate concentrations decreased from $\mathrm{d}-2$ to $\mathrm{d} 49$ in control heifers, while remaining constant in A2P-fed animals. Across treatments, plasma ascorbate was highest at $\mathrm{d}-2$ and lowest at d $28(P<0.05)$.

Plasma IgG concentrations were not affected by diet at anytime during the study $(P>0.1$, Tables 3 and 4$)$. Mean concentrations were $2552 \pm 342(\mathrm{SEM}) \mathrm{mg} / \mathrm{dl}$ for control heifers and $2435 \pm 421 \mathrm{mg} / \mathrm{dl}$ in A2P-fed heifers.

\section{PWM}

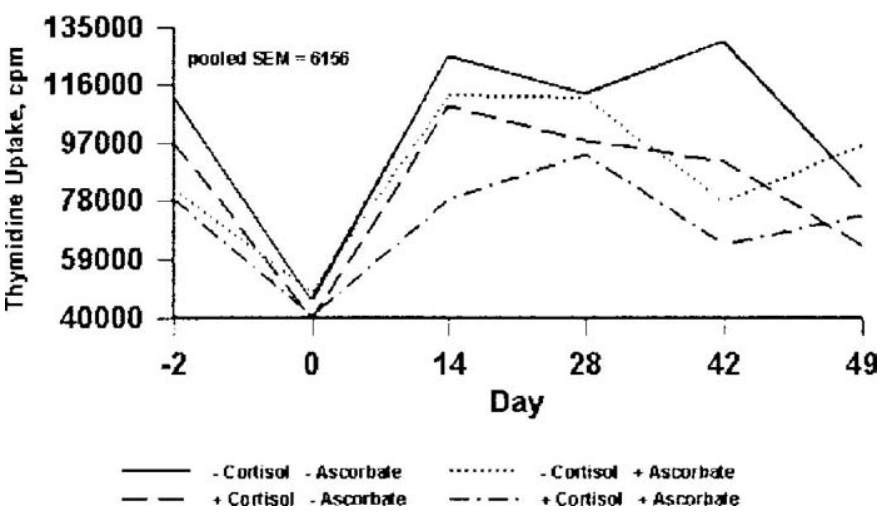

Figure 2. Proliferation of mononuclear lymphocytes stimulated with pokeweed mitogen (PWM). Proliferation was evaluated by ${ }^{3} \mathrm{H}-$ methyl thymidine uptake. Day 0 was day of transport $210 \mathrm{~km}$ to feeding facility. Effect of cortisol $(P<0.001)$, dietary ascorbate $(P<$ $0.1)$ and interaction of day of study and dietary ascorbate $(P<0.1)$ were significant. 
Table 3. Plasma concentrations of cortisol, ascorbate, IgG, and antibody titers to keyhole limpet hemocyanin $(\mathrm{KLH})$ during the experimental period for control (CON) and ascorbyl-2-phosphate (A2P) fed heifers.

\begin{tabular}{|c|c|c|c|c|c|c|c|c|}
\hline \multirow[b]{2}{*}{ Day } & \multicolumn{2}{|c|}{ Cortisol, $\mu \mathrm{g} / \mathrm{ml}$} & \multicolumn{2}{|c|}{ Ascorbate, mg/dl } & \multicolumn{2}{|c|}{$\mathrm{IgG}, \mathrm{mg} / \mathrm{dl}$} & \multicolumn{2}{|c|}{$\begin{array}{l}\text { Antibody titer } \\
\text { to } \mathrm{KLH}, \log _{10}\end{array}$} \\
\hline & $\mathrm{CON}$ & $\mathrm{A} 2 \mathrm{P}$ & $\mathrm{CON}$ & $\mathrm{A} 2 \mathrm{P}$ & $\mathrm{CON}$ & $\mathrm{A} 2 \mathrm{P}$ & $\mathrm{CON}$ & $\mathrm{A} 2 \mathrm{P}$ \\
\hline 7 & 19.6 & 17.0 & $0.15^{\mathrm{a}}$ & $0.24^{\mathrm{b}}$ & 2598 & 2320 & $2.43^{\mathrm{d}}$ & $2.23^{\mathrm{c}}$ \\
\hline 14 & 14.1 & 18.4 & $\ldots$ & $\ldots$ & 2640 & 2440 & $2.61^{\mathrm{d}}$ & $2.35^{\mathrm{c}}$ \\
\hline 21 & 12.9 & 17.3 & & & 2510 & 2420 & $2.88^{\mathrm{d}}$ & $2.71^{\mathrm{c}}$ \\
\hline 28 & 11.1 & 11.8 & 0.08 & 0.13 & 2500 & 2490 & $2.84^{\mathrm{d}}$ & $2.60^{\mathrm{c}}$ \\
\hline 35 & 11.7 & 12.9 & $\ldots$ & $\ldots$ & 2540 & 2460 & $2.76^{\mathrm{d}}$ & $2.38^{\mathrm{c}}$ \\
\hline 42 & 6.5 & 12.6 & & & 2450 & 2390 & $2.73^{\mathrm{d}}$ & $2.32^{\mathrm{c}}$ \\
\hline 49 & 10.7 & 12.4 & 0.11 & 0.16 & 2470 & 2280 & $2.47^{\mathrm{d}}$ & $2.14^{\mathrm{c}}$ \\
\hline Pooled SEM & 1.9 & 1.7 & 0.03 & 0.02 & 35 & 35 & 0.06 & 0.05 \\
\hline
\end{tabular}

${ }^{\mathrm{a}, \mathrm{b}}$ Values for ascorbate without common superscript are significantly different, $P<0.1$.

${ }^{\mathrm{c}, \mathrm{d}}$ Values for $\mathrm{KLH}$ antibody titer without common superscript are significantly different, $P<0.05$.

Antibody titers to KLH showed significant diet $(P<$ $0.05)$ and day $(P<0.05)$ effects, with animals fed A2P having lower titers of $\mathrm{KLH}$ antibodies as compared to the control heifers (Table 3). KLH antibody titers peaked at d 21 for both diets.

Proliferation of MNL following stimulation with mitogens is shown in Figures 1 through 4. There were significant effects of cortisol, mitogen, and a mitogen $x$ cortisol interaction $(P<0.001)$. There were also significant interactions of cortisol $\times$ day $(P<0.05)$, diet $\times$ day $(P<0.1)$, and diet $\times$ mitogen $(P<0.1)$. Thymidine incorporation was decreased on $\mathrm{d} 0$ across all treatments $(P<0.01)$, and increased until after d 28. Cortisol addition to the media had the greatest effect on ${ }^{3} \mathrm{H}$ methyl thymidine incorporation on $\mathrm{d} 0(P<0.05)$. Cortisol addition to the incubation media resulted in decreased MNL ${ }^{3} \mathrm{H}$-methyl thymidine incorporation $(P<$ 0.001) in all MNL except those stimulated with CONA, where cortisol addition without dietary A2P had no effect.

\section{DISCUSSION}

Transport of the heifers increased plasma cortisol concentrations on $\mathrm{d} 0$ relative to $\mathrm{d}-2$ (Table 4). How- ever, the effect was transient, as plasma cortisol concentrations had returned to baseline by d 7 of the experimental period. A study by Crookshank et al. (1979) showed that plasma levels of cortisol return to normal between 4 and $7 \mathrm{~d}$ after transport. Plasma ascorbate also decreased on d 0 relative to $\mathrm{d}-2$ (Table 4). Lower plasma ascorbate associated with increased plasma cortisol has been reported previously in calves as a result of confinement housing or active infections (Salageanu et al., 1971; Cummins and Brunner, 1990).

Heifers fed A2P had higher ADG and feed efficiency from days 28 to 49 (Table 2). However, over the entire $49 \mathrm{~d}$ experiment, ADG and feed efficiency were not affected by diet. The reasons for the improved ADG and feed efficiency during the second half of the experimental period are obscure.

Plasma ascorbate was higher on d 7 in A2P fed heifers (Table 3). Ascorbic acid is rapidly destroyed in the rumen, and feeding ascorbic acid generally does not result in increased plasma ascorbate concentrations in cattle (Knight et al., 1941). However, dietary supplementation with ascorbic acid in the form of $\mathrm{A} 2 \mathrm{P}$ may result in biologically available ascorbate being absorbed from the digestive tract of heifers with functional rumens, as evidenced by increased plasma ascorbate at $d 7$ of

Table 4. Plasma concentrations of cortisol, IgG, ascorbic acid, and antibody titers to keyhole limpet hemocyanin on $\mathrm{d}-2$ before transport and d 0 immediately following transport.

\begin{tabular}{lccc}
\hline & \multicolumn{2}{c}{ Day } & Pooled \\
\cline { 2 - 4 } & -2 & $0^{1}$ & SEM \\
\hline Cortisol, $\mu \mathrm{g} / \mathrm{ml}^{\mathrm{a}}$ & 16.2 & 41.8 & 1.67 \\
$\mathrm{IgG}, \mathrm{mg} / \mathrm{dl}$ & 2440 & 2310 & 27.0 \\
Ascorbic acid, $\mathrm{mg} / \mathrm{dl}^{\mathrm{a}}$ & 0.24 & 0.13 & 0.04 \\
Antibody titer to KLH, $\log _{10}{ }^{2}$ & 1.94 & 1.93 & 0.01 \\
\hline
\end{tabular}

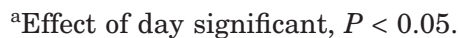

${ }^{1}$ Samples taken immediately following transport.

${ }^{2}$ Heifers had not yet been injected with KLH. 
the experimental period in heifers fed A2P. A study by MacLeod et al. (1996) showed increases of ascorbic acid in both plasma and muscle with ascorbyl-2-polyphosphate (A2PP). The levels of A2PP that were fed in the study by MacLeod et al. (1996) were higher than levels of $\mathrm{A} 2 \mathrm{P}$ in this study and might have been a reason for the differences in this study as well as the difference in type of ascorbic acid form.

During the experimental period, dietary ascorbate had no effect on plasma cortisol $(P>0.1$, Table 3$)$. This is in contrast to the observations in guinea pigs by Doulas et al. (1987), in which guinea pigs given greater than $5 \mathrm{mg} / 100 \mathrm{~g}$ of BW of ascorbic acid had cortisol levels that were decreased when compared to animals fed $0.1 \mathrm{mg} / 100 \mathrm{~g}$ of BW or less. Intake of ascorbate in this heifer study was approximately $1.3 \mathrm{mg} / 100 \mathrm{~g}$ of $\mathrm{BW}$, which is much lower than the intake in the study by Doulas et al. (1987). Further studies feeding higher levels of $\mathrm{A} 2 \mathrm{P}$ to heifers must be done to determine if A2P can affect plasma cortisol levels. Plasma cortisol concentrations decreased over the experimental period, possibly as the heifers became acclimated to the blood sampling procedure.

Plasma IgG concentrations were not affected by diet and the heifers in both dietary groups had plasma IgG concentrations within normal ranges for this species and age of animal (Table 3). Heifers in both dietary groups showed significant antibody production to $\mathrm{KLH}$, as titers increased until d 21 of the study (Table 3). Plasma antibody titers to $\mathrm{KLH}$ were lower in heifers fed A2P $(P<0.001$, Table 3$)$. In a study by Hidiroglou et al. (1995), newborn calves were not found to have any change in KLH titers due to ascorbic acid supplementation. However, lower antibody titers to KLH in response to ascorbic acid have been reported in calves fed ascorbate and housed and managed so as to not be under conditions of undue stress (Cummins and Brunner, 1989). The mechanism by which ascorbate may affect antibody production has yet to be elucidated.

In MNL cultured without a mitogen, dietary A2P resulted in increased $\mathrm{MNL}{ }^{3} \mathrm{H}$-methyl thymidine incorporation during the experimental period (Figure 1). This effect has been previously reported in mice fed another antioxidant vitamin, vitamin $\mathrm{E}$ (Corwin and Gordon, 1982), although both the significance of unstimulated MNL ${ }^{3} \mathrm{H}$-methyl thymidine incorporation and a possible mechanism for the increased thymidine incorporation associated with increased availability of antioxidant vitamins is unknown. Unstimulated MNL also had decreased thymidine incorporation in response to addition of cortisol to the incubation media $(P<$ 0.001), and there was an interaction between cortisol addition to the incubation media and dietary A2P $(P<$ 0.05 , Figure 1). Thymidine incorporation in unstimu-

\section{Con A}

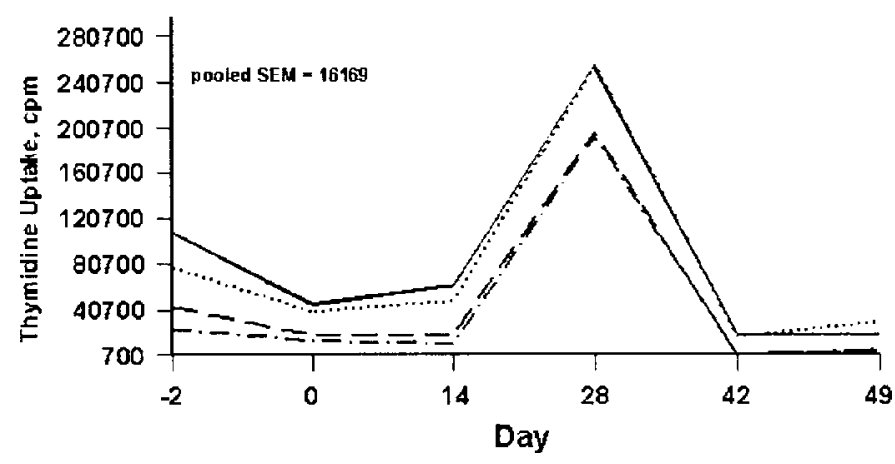

Figure 3. Proliferation of mononuclear lymphocytes stimulated with concanavalin A (ConA). Proliferation was evaluated by ${ }^{3} \mathrm{H}-$ methyl thymidine uptake. Day 0 was day of transport $210 \mathrm{~km}$ to feeding facility. Effect of cortisol and interaction of cortisol and day of study were significant $(P<0.01)$.

lated MNL was lower in cells incubated with cortisol than those incubated without cortisol, an effect which has also been demonstrated in bovine MNL incubated without mitogens after cortisol was increased in vivo after transportation (Murata et al., 1987). Addition of $\mathrm{A} 2 \mathrm{P}$ to diets of heifers resulted in increased ${ }^{3} \mathrm{H}$-methyl thymidine incorporation in MNL not incubated with cortisol but appeared to have little effect on MNL incubated with cortisol.

Dietary A2P reduced proliferation of MNL following stimulation with PWM $(P<0.1$, Figure 2$)$, although there was a significant interaction between the effect of dietary A2P and day of study $(P<0.1)$. The decrease in proliferation of PWM stimulated cells has also been demonstrated with physiological amounts of ascorbic acid added to porcine MNL in vitro (Schwager and Schulze, 1997). Addition of ascorbate to incubation media has been previously demonstrated to decrease human MNL proliferation in response to stimulation with ConA and PHA (Ramirez et al., 1980), an effect not observed in this study utilizing dietary ascorbate. In another study, ascorbic acid supplementation of 2- and 4-wk-old unstressed calves did not affect lymphocyte proliferation in MNL cells incubated with PWM, ConA or PHA (Eicher-Pruiett et al., 1992). The negative effect of ascorbate on MNL proliferation in vitro was dose dependent and, while apparent up to $96 \mathrm{~h}$ after the start of incubation, was greatest when ascorbate was added to the media immediately upon the start of incubation. Ramirez et al. (1980) suggested that ascorbate had an effect on early events during MNL proliferation. Another study reported that lower quantities of added ascorbate enhanced the response to PHA (Standefer et al., 1987). In our study, dietary A2P had a negative 


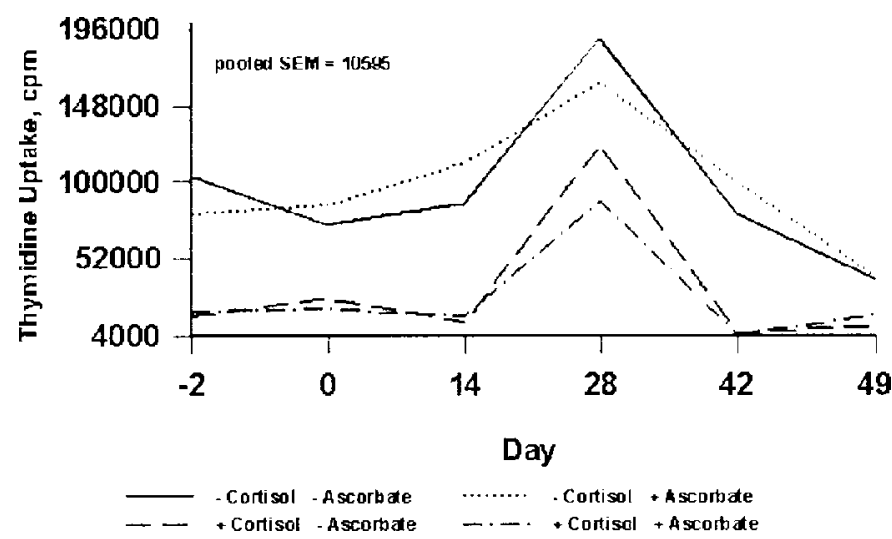

Figure 4. Proliferation of mononuclear lymphocytes stimulated with phytohemagglutinin (PHA). Proliferation was evaluated by ${ }^{3} \mathrm{H}$ methyl thymidine uptake. Day 0 was day of transport $210 \mathrm{~km}$ to feeding facility. Effect of cortisol $(P<0.001)$, interaction of day of study and dietary ascorbate $(P<0.05)$, and interaction of day of study and cortisol $(P<0.01)$ were significant.

effect on cell proliferation in cultures stimulated with PWM, and no effect on stimulation with either ConA or PHA (Figures 2, 3, and 4).

Cortisol addition to the culture media uniformly decreased $\mathrm{MNL}{ }^{3} \mathrm{H}$-methyl thymidine incorporation in MNL stimulated with PWM, ConA, or PHA $(P<0.001$, Figures 2, 3, and 4). Cortisol has been shown to decrease MNL proliferation in vitro in response to stimulation with both PHA and ConA (Gillis et al., 1979, Blecha and Baker, 1986). Another study found little or no effect of cortisol on MNL proliferation in human cells stimulated with PWM (Rupprecht et al., 1990-1991). Sustained elevated concentrations of cortisol in vitro and in vivo also have been shown to decrease interleukin2 production (Blecha and Baker, 1986). There was an interaction of day of study and cortisol addition to the incubation media for MNL stimulated with ConA and PHA, with the magnitude of the decrease in MNL ${ }^{3} \mathrm{H}$ methyl thymidine uptake as a result of cortisol addition to the incubation media varying at different days of the study ( $P<0.01$; Figures 3 and 4$)$. Cortisol caused the smallest decrease in ${ }^{3} \mathrm{H}$-methyl thymidine uptake in PHA stimulated cells on $\mathrm{d} 49$ and the smallest decrease in ${ }^{3} \mathrm{H}$-methyl thymidine uptake in ConA stimulated cells on d 28 with no regular pattern according to day of study.

While the significance of the rate of unstimulated ${ }^{3} \mathrm{H}$-methyl thymidine incorporation in peripheral $\mathrm{MNL}$ isolated from whole blood samples is not known, regression analysis indicates that for certain experimental conditions, there was a linear relationship between unstimulated and stimulated ${ }^{3} \mathrm{H}$-methyl thymidine incorporation (Table 5). This relationship varied with the mitogen used, whether cortisol was added to the incubation media, and the addition of A2P to the diet. For PWM, a B-cell and helper T-cell mitogen, there was a linear relationship between stimulated and unstimulated ${ }^{3} \mathrm{H}$-methyl thymidine incorporation without cortisol added to the incubation media. The addition of cortisol resulted in nonsignificant regressions of unstimulated vs. stimulated thymidine incorporation in MNL stimulated with PWM $(P>0.1)$. The addition of cortisol also had an affect on the relationship between stimulated and unstimulated thymidine incorporation for MNL stimulated with ConA or PHA, which are predominately T-cell mitogens, possibly by decreasing the interleukin 2 production necessary for proliferation (Blecha and Baker, 1986). However, if the MNL were collected from heifers fed A2P, regression of stimulated thymidine incorporation on unstimulated incorporation was not significant $(P>0.1)$ whether cortisol was in the medium or not. The mechanism by which dietary A2P and physiological concentrations of cortisol affect the relationship between stimulated and unstimulated thymidine incorporation remains to be elucidated, but previously observed affects of cortisol on interleukin production (Blecha and Baker, 1986) and ascorbate on MNL proliferation may be involved (Ramirez et al., 1980; Schwager and Schulze, 1997).

Table 5. Equations for regression of stimulated ${ }^{3} \mathrm{H}$-methyl thymidine incorporation $(\mathrm{Y})$ on unstimulated ${ }^{3} \mathrm{H}$-methyl thymidine incorporation (X).

\begin{tabular}{|c|c|c|c|c|c|c|}
\hline \multirow[b]{2}{*}{ Mitogen } & \multicolumn{2}{|c|}{ Treatment } & \multirow[b]{2}{*}{ Equation } & \multirow[b]{2}{*}{$\mathrm{r}^{2}$} & \multirow[b]{2}{*}{$P$ value } & \multirow[b]{2}{*}{ Slope $^{a}$} \\
\hline & $\mathrm{A} 2 \mathrm{P}$ & Cortisol & & & & \\
\hline Pokeweed mitogen & $\cdots$ & $\begin{array}{l}\cdots \\
\cdots\end{array}$ & $\begin{array}{l}\mathrm{Y}=90,878+3.95 \mathrm{X} \\
\mathrm{Y}=87,463+0.99 \mathrm{X}\end{array}$ & $\begin{array}{l}0.1 \\
0.11\end{array}$ & $\begin{array}{l}0.1 \\
0.05\end{array}$ & NS \\
\hline Concanavalin A & $\begin{array}{l}\ldots \\
\ldots\end{array}$ & $\begin{array}{l}\cdots \\
+\end{array}$ & $\begin{array}{l}\mathrm{Y}=44,529+7.86 \mathrm{X} \\
\mathrm{Y}=3554+69.4 \mathrm{X}\end{array}$ & $\begin{array}{l}0.09 \\
0.21\end{array}$ & $\begin{array}{l}0.1 \\
0.01\end{array}$ & 0.05 \\
\hline Phytohemagglutinin & $\begin{array}{l}\cdots \\
\cdots\end{array}$ & $\begin{array}{l}\cdots \\
+\end{array}$ & $\begin{array}{l}Y=42,215+10.1 X \\
Y=-8962+60 X\end{array}$ & $\begin{array}{l}0.3 \\
0.33\end{array}$ & $\begin{array}{l}0.001 \\
0.001\end{array}$ & 0.01 \\
\hline
\end{tabular}

${ }^{\text {a } P}$ value for slopes of regression lines within mitogen being different by heterogeneity of regression analysis. NS $=$ Not significant. 
The effects of cortisol and A2P on MNL proliferation following stimulation with a mitogen appear to vary with the mitogen used and the population of cells affected. In vivo injections of dexamethasone and ascorbate have both been shown to affect neutrophil function (Roth and Kaeberle, 1985). Dexamethasone decreased neutrophil function as measured by Staphylococcus aureus ingestion and random migration, and subcutaneous ascorbate injections decreased the negative effects of dexamethasone on neutrophil function (Roth and Kaeberle, 1985). The possible effects of ascorbate during the early metabolic or signaling events of an immune response could also be responsible for the decreased antibody titers to KLH and lower plasma IgG concentrations observed in this and a previous study (Cummins and Brunner, 1989).

\section{CONCLUSION}

Dietary A2P may offer a means to increase plasma ascorbate concentrations in mature ruminants. Whereas transportation appears to act as a stressor in cattle and transiently increase plasma cortisol concentrations, dietary $\mathrm{A} 2 \mathrm{P}$ supplementation does not appear to improve immune response as evaluated by antibody production or MNL proliferation assay, although the effect may differ in various populations of MNL. Dietary $\mathrm{A} 2 \mathrm{P}$ appeared to have the same effect as previously reported for in vitro addition of ascorbate, decreasing MNL proliferation following stimulation with a mitogen. Basal levels of MNL thymidine-incorporation were increased due to dietary $\mathrm{A} 2 \mathrm{P}$, but the significance of this observation is not immediately apparent. Cells of the immune system do appear to respond to differing ascorbate concentrations, but the effects are often negative as well as positive. The value of dietary A2P supplementation under conditions of long-term exposure to a stressor remain to be investigated, as does the effects of ascorbate on the early events of an immune response.

\section{REFERENCES}

Agnes, F., P. Sartorelli, B. H. Abdi, and A. Locatelli. 1990. Effect of transport loading or noise on blood biochemical variables in calves. Am. J. Vet. Res. 51:1679-1681.

Anderson, R., and P. T. Lukey. 1987. A biological role for ascorbate in the selective neutralization of extracellular phagocyte-derived oxidants. Ann. N.Y. Acad. Sci. 498:229-247.

Blecha, F., and P. E. Baker. 1986. Effect of cortisol in vitro and in vivo on production of bovine interleukin 2 . Am. J. Vet. Res. 47:841-845.

Corwin, L. M., and R. K. Gordon. 1982. Vitamin E and immune regulation. Ann. N.Y. Acad. Sci. 393:437-451.
Crookshank, H. R., M. H. Elissalde, R. G. White, D. C. Clanton, and H. E. Smalley. 1979. Effect of transportation and handling of calves upon blood serum composition. J. Anim. Sci. 48:430-435.

Cummins, K. A., and C. J. Brunner. 1989. Dietary ascorbic acid and immune response in dairy calves. J. Dairy Sci. 72:129-134.

Cummins, K. A., and C. J. Brunner. 1990. Effect of calf housing on plasma ascorbate and endocrine and immune function. J. Dairy Sci. 74:1582-1588.

Cupps, T. R., and A. S. Fauci. 1982. Corticosteroid-mediated immunoregulation in man. Immunol. Rev. 65:133-155.

Doulas, N. L., A. Constantopoulas, and B. Litsios. 1987. Effect of ascorbic acid on guinea pig adrenal adenylate cyclase activity and plasma cortisol. J. Nutr. 117:1108-1114.

Eicher-Pruiett, S. D., J. L. Morrill, F. Blecha, J. J. Higgins, N. V. Anderson, and P. G. Reddy. 1992. Neutrophil and lymphocyte response to supplementation with vitamins $\mathrm{C}$ and $\mathrm{E}$ in young calves. J. Dairy Sci. 75:1635-1642.

Fell, L. R., and D. A. Shutt. 1986. Adrenocortical response of calves to transport stress as measured by salivary cortisol. Can. J. Anim. Sci. 66:637-641.

Gillis, S., G. R. Crabtree, and K. A. Smith. 1979. Glucocorticoidinduced inhibition of $\mathrm{T}$ cell growth factor production. I. The effect on mitogen-induced lymphocyte proliferation. J. Immunol. 123:1624-1631.

Goldshmidt, M. C. 1991. Reduced bactericidal activity in neutrophils from scorbutic animals and the effect of ascorbic acid on these target bacteria in vivo and in vitro. Am. J. Clin. Nutr. $54: 1214 \mathrm{~s}-1220 \mathrm{~s}$.

Hidiroglou, M., T. R. Batra, and M. Ivan. 1995. Effects of supplemental vitamins $\mathrm{E}$ and $\mathrm{C}$ on the immune responses of calves. J. Dairy Sci. 78:1578-1583.

Knight, C. A., R. A. Dutcher, N. B. Guerrant, and S. I. Bechdel. 1941. Utilization and excretion of ascorbic acid by the dairy cow. J. Dairy Sci. 24:567-577.

MacLeod, D. D., X. Zhang, J. J. Kennelly, and L. Ozimek. 1996. Ascorbyl-2-polyphosphate as a source of ascorbic acid for dairy cattle. J. Dairy Sci. 79(Suppl. 1):188. (Abstr.)

Mitchell, G., J. Hattingh, and M. Ganhao. 1988. Stress in cattle assessed after handling, after transport and after slaughter. Vet. Rec. 123:201-205.

Murata, H., H. Takahashi, and H. Matsumoto. 1987. The effects of road transportation on peripheral blood lymphocyte subpopulations, lymphocyte blastogenesis and neutrophil function in calves. Br. Vet. J. 143:166-174.

National Research Council. 1988. Nutrient Requirements of Dairy Cattle. 6th rev. ed. National Academy Press, Washington, DC.

Ojo-Amaize, E. A., A. J. Guidry, M. Paape, and H. K. Mayer. 1988. In vitro depression of bovine lymphocytes with physiologic concentrations of hydrocortisone. Am. J. Vet. Res. 49:851-855.

Okamura, M. 1980. An improved method for determination of Lascorbic acid and L-dehydroascorbic acid in blood plasma. Clin. Chim. Acta 103:259-268.

Parrillo, J. E., and A. S. Fauci. 1979. Mechanisms of glucocorticoid action on immune processes. Annu. Rev. Pharmacol. Toxicol. 19:179-201.

Ramirez, I., E. Ritchie, Y. Wang, and J. Van Eys. 1980. Effect of ascorbic acid in vitro on lymphocyte reactivity to mitogens. J. Nutr. 110:2207-2215.

Roth, J. A., and M. L. Kaeberle. 1982. Effect of glucocorticoids on the bovine immune system. J. Am. Vet. Med. Assoc. 180:894-901.

Roth, J. A., and M. L. Kaeberle. 1985. In vivo effect of ascorbic acid on neutrophil function in healthy and dexamethasone-treated cattle. Am. J. Vet. Res. 46:2434-2436.

Rupprecht, R., N. Wodarz, J. Kornhuber, B. Schmitz, K. Wild, H. U. Braner, O. A. Müller, and P. Riederer. 1990-1991. In vivo and in vitro effects of glucocorticoids on lymphocyte proliferation in man: relationship to glucocorticoid receptors. Neuropsychobiology 24(2):61-66

Salageanu, G., D. Curca, I. Ursa, and A. Batrinu. 1971. Hypovitaminosis $\mathrm{C}$ in newborn calves with enteropathies. Rev. Zootech. Med. Vet. 21:57-63. 
Sartin, J. L., R. J. Kemppainen, K. A. Cummins, and J. C. Williams. 1988. Plasma concentrations of metabolic hormones in high and low producing dairy cows. J. Dairy Sci. 71:650-657.

SAS User's Guide: Basics. 1985. SAS Inst., Inc., Cary, NC.

Sato, M., T. Miyasaki, and R. Yoshinaka. 1991. Utilization of 1 ascorbyl-2-phosphate in rainbow trout as a dietary vitamin $\mathrm{C}$ source. Nippon Suisan Gakkaishi 57:1923-1926.

Schwager, J., and J. Schulze. 1997. Influence of ascorbic acid on the response to mitogens and interleukin production of porcine lymphocytes. Int. J. Vit. Nutr. Res. 67:10-16.
Shigueno, K., and S. Itoh. 1988. Use of Mg-L-ascorbyl-2-phosphate as a vitamin $\mathrm{C}$ source in shrimp diets. J. World Aqua. Soc. 19:168-174.

Standefer, J. C., D. Vanderjagt, R. E. Anderson, P. J. Garry, and L. Pogue. 1987. Protective effect of ascorbate on radiation-sensitive thymidine uptake by lymphocytes. Ann. N.Y. Acad. Sci. 498:519-521.

Vavich, M. G., R. A. Dutcher, N. B. Guerrant, and S. I. Bechdel. 1945. Utilization and excretion of ingested ascorbic acid by the dairy cow. J. Dairy Sci. 28:759-770. 